\title{
An Exploratory Study of the Effects of the pH of Synthetic Urine on Skin Integrity in Healthy Participants
}

\author{
Sofoklis Koudounas ${ }^{\mathrm{a}}$ Dan L. Bader ${ }^{\mathrm{a}}$ David Voegeli ${ }^{\mathrm{b}}$ \\ aSkin Health Research Group, School of Health Sciences, Faculty of Environmental and Life Sciences, University of

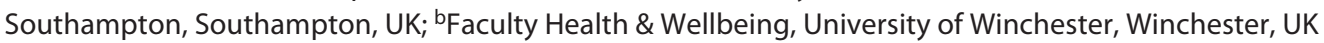

\section{Keywords}

Acid mantle $\cdot$ Incontinence-associated dermatitis $\cdot$ Skin barrier · Skin health · Synthetic urine

\begin{abstract}
Background: Incontinence-associated dermatitis (IAD) develops from prolonged exposure of skin to urine and/or stool and represents a common complication in older adults, reducing the quality of life. Increased $\mathrm{pH}$ is an important etiologic factor of IAD; however, the relationship between urinary $\mathrm{pH}$ and skin barrier disruption remains unclear. Objective: The aim of this study is to examine the effects of synthetic urine (s-urine) at various $\mathrm{pHs}$ on transepidermal water loss (TEWL), stratum corneum hydration (SCH), and skin surface $\mathrm{pH}$. Methods: S-urine solutions ( $\mathrm{pH}$ 5.0-9.0) were applied to the volar forearms of 15 healthy participants for $2 \mathrm{~h}$, with another site serving as the untreated control. Measurements of TEWL, SCH, and skin surface $\mathrm{pH}$ were obtained at baseline (BL) and after each challenge. Skin buffering capacity was also examined in 5 volunteers by recording skin $\mathrm{pH}$ at $\mathrm{BL}$, after $2 \mathrm{~h}$ exposure and every $5 \mathrm{~min}$ for $40 \mathrm{~min}$. Results: TEWL and $\mathrm{SCH}$ were increased following exposure to s-urine compared to BL values. Although there was a ten-
\end{abstract}

Karger@karger.com www.karger.com/spp

Karger $\stackrel{\text { ' }}{5}$

GOPEN ACCESS
(C) 2022 The Author(s)

Published by S. Karger AG, Basel

This is an Open Access article licensed under the Creative Commons Attribution-NonCommercial-4.0 International License (CC BY-NC) (http://www.karger.com/Services/OpenAccessLicense), applicable to the online version of the article only. Usage and distribution for commercial purposes requires written permission. dency for $\mathrm{pH}$ to increase after exposure, further investigation showed that changes are only temporal as $\mathrm{pH}$ value is restored to BL within 5 mins. There were no significant differences between solutions. Conclusions: This study revealed that urine disrupts healthy skin integrity; however, its effects are not $\mathrm{pH}$ dependent. Transient changes were observed on the acid mantle of the skin due to its innate buffering capacity. Future studies need to examine the effects of urine combined with bacteria responsible for $\mathrm{pH}$ elevation in patients with urinary incontinence.

(c) 2022 The Author(s)

Published by S. Karger AG, Basel

\section{Introduction}

Incontinence-associated dermatitis (IAD) is classified by the ICD-11 [1] as a form of irritant contact dermatitis caused by the prolonged exposure of the skin to urine, faeces, or both and represents a common complication in adults with incontinence $[2,3]$. The initial clinical signs of IAD include persistent erythema and inflammation at the skin surface, and if left untreated, can lead to edema, swelling, and blister formation [2]. Affected individuals may experience pain, discomfort, burning, and itching, 
that ultimately reduces the quality of life, and are also at increased risk of developing pressure injuries $[4,5]$. Prevalence and incidence of IAD vary depending on the care setting, with higher rates commonly seen in acute care settings (19-45.7\%) $[4,6-8]$ than in long-term care facilities (4.3-8.4\%) $[6,9,10]$ with corresponding incidence rates of $5.2-46.1 \%[4,6,8,9,11]$ and $3.4-25 \%$, respectively [12-14].

The physical barrier of the skin resides in the stratum corneum (SC) with the important functions of cohesion, homeostasis, the regulation of water diffusion, a process associated with transepidermal water loss (TEWL) [15], and the protection of the body from various insults, involving microbes and UV light [16]. The acidic $\mathrm{pH}$ of the skin surface, known as the acid mantle [17], is a critical regulator of SC function [18] and any alterations in $\mathrm{pH}$ will impair the barrier, enhance the penetration of substances, inhibit normal skin microbiota, and promote the growth of pathogens [19-21]. By exhibiting a pH between 4 and 6, the skin surface provides an optimum environment for the activity of key enzymes involved in desquamation and ceramide synthesis, such as serine proteases and $\beta$-glucocerebrosidase, for the formation of lamellar bilayers, which are critical for skin permeability, and for the recovery rate of the barrier function in pathogenic conditions [21-27]. Therefore, TEWL, SC hydration $(\mathrm{SCH})$, and skin's acidity are important physiological properties for the maintenance of skin integrity and consequently, high values of these parameters are associated with an impaired barrier $[15,28]$.

In incontinent patients, exposure to urine for extensive periods of time macerates the skin, leading to an overhydrated epidermis, swelling of corneocytes in the SC, barrier disruption, and enhanced upregulation of proinflammatory cytokines [29-31]. The damage is aggravated in the presence of urease-producing bacteria from the perineum or the nearby urinary tract that convert urea in urine into ammonia. This converts skin $\mathrm{pH}$ to alkaline levels which can activate lipolytic and proteolytic enzymes from the gut and excreted in faeces [32-34]. Elevated surface $\mathrm{pH}$, in turn, increases skin permeability thus irritating the effects of incontinence [35] and promoting microbial growth and IAD development $[36,37]$. Indeed, previous studies have reported that even shortterm exposure to alkaline urine, results in erythema, with an associated increase in TEWL, $\mathrm{SCH}$, and skin $\mathrm{pH}$, and an eventual compromise to skin barrier functionality [38, 39]. In particular, an increase in urinary $\mathrm{pH}$ was associated with more severe disruption of barrier function [39]. However, previous studies investigating this, employed alkaline urinary values ( $\mathrm{pH} 7.9-10.7)$, which are beyond those of biological urine ranging from $\mathrm{pH} 4.5$ to $\mathrm{pH} 8.0$ $[40,41]$, depending on several factors, including diet and the presence of infection $[40,42]$. As a consequence, the exact relationship between urinary $\mathrm{pH}$ and disruption of skin integrity is still unknown. The present study examined the effects of synthetic urine (s-urine) at various $\mathrm{pH}$ values of physiological relevance on biophysical parameters characterizing healthy skin integrity.

\section{Methods}

\section{Study Design and Setting}

This study represents an exploratory study approved by the Ethics Committee of University of Southampton (approval number 9349) and conducted within a bioengineering laboratory under controlled temperature $\left(22^{\circ} \mathrm{C} \pm 3^{\circ} \mathrm{C}\right)$ and humidity $(40-45 \%)$ conditions, as these influence measurements [43-47]. Although this did not represent a randomized control trial, we adhered to the CONSORT statement guidelines for the reporting of this study [48].

\section{Participants}

Previously published data using the measures of skin barrier function suggested that a change of $25 \%$ was detectable using 15 subjects with $80 \%$ power and significance at a significance level of $5 \%$ [49]. The inclusion criteria for recruiting participants were (1) aged 18-65 years, (2) no active skin disease, and (3) no previous history of skin diseases. Exclusion criteria included pregnancy, preexisting medical condition that is known to affect the dermal vasculature (e.g., diabetes mellitus), treatment with any vasoactive medication (e.g., $\beta$-blockers, nonsteroidal anti-inflammatory drugs, steroids), preexisting dermatological condition, and inability to give informed written consent. Participation was voluntary and no incentives were provided. Participants were asked to refrain from applying any cosmetic products to the forearms for $12 \mathrm{~h}$ before the study, to avoid influence on biophysical measurements $[46,50]$. Informed consent was obtained from the participants upon arrival to the laboratory and after the details of the procedures had been fully explained. All study procedures complied with the principles outlined in the Helsinki Declaration and participants were left to acclimatize to the ambient conditions for $30 \mathrm{mins}$ prior to testing.

\section{Synthetic Human Urine}

To simulate the moisture irritant source experienced by patients with urinary incontinence, s-urine ( $\mathrm{pH}$ of 7.9) was used as previously described [51]. In brief, $25 \mathrm{~g}$ urea (Fisher Scientific, UK), 9 g sodium chloride (Sigma Aldrich, UK), 3 g ammonium chloride (Fisher Scientific, UK), 3 g sodium sulphite (Fisher Scientific, UK), $2.5 \mathrm{~g}$ anhydrous disodium hydrogen orthophosphate (Fisher Scientific, UK), and 2 g creatinine (Across Organics, Geel, Belgium) were dissolved in $1 \mathrm{~L}$ of distilled water and kept at $4^{\circ} \mathrm{C}$. S-urine $\mathrm{pH}$ was adjusted to values from 5.0 to 9.0 with $1 \mathrm{M}$ hydrochloric acid and $1 \mathrm{M}$ ammonium hydroxide.

\section{Skin Integrity Assessment}

Skin integrity was evaluated using noninvasive biophysical measurement techniques. TEWL was quantified using the open- 

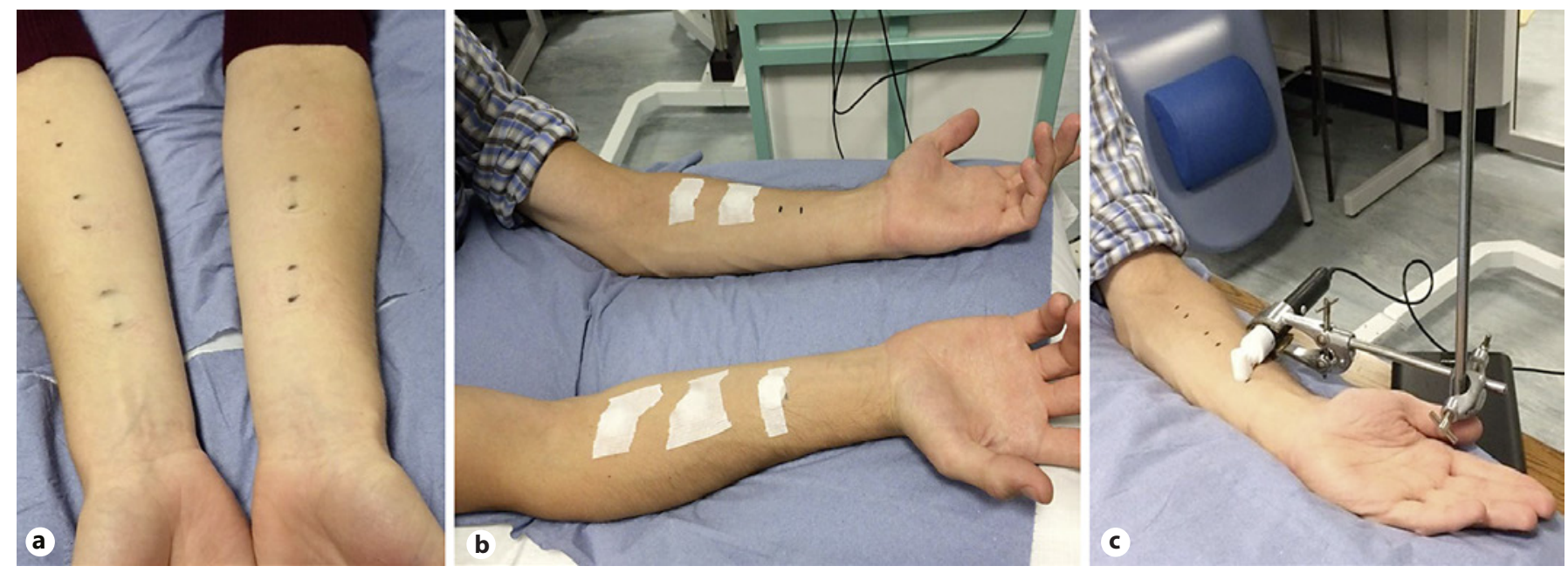

Fig. 1. Application of s-urine solutions. Six skin sites were marked on both volar forearms (a), and HillTop chambers were impregnated with $500 \mu \mathrm{L}$ s-urine and applied to the skin using a medical tape to keep them in place (b). A sixth site served as the untreated control. c Prior to each treatment and after exposure, TEWL was measured to assess skin barrier disruption with the Tewameter ${ }^{\circledR}$ TM 300.

Table 1. Median differences from BL and \% change for each skin integrity parameter following exposure to s-urine at different $\mathrm{pH}$ values

\begin{tabular}{|c|c|c|c|c|c|c|}
\hline & \multicolumn{2}{|c|}{ TEWL, $\mathrm{g} / \mathrm{h} / \mathrm{m}^{2}$} & \multicolumn{2}{|l|}{ SCHAUs } & \multicolumn{2}{|c|}{ Skin surface $\mathrm{pH}$ units } \\
\hline & $\begin{array}{l}\text { Median } \\
\text { difference }\end{array}$ & $\%$ change & $\begin{array}{l}\text { Median } \\
\text { difference }\end{array}$ & $\%$ change & $\begin{array}{l}\text { Median } \\
\text { difference }\end{array}$ & $\begin{array}{l}\% \\
\text { change }\end{array}$ \\
\hline Control & -0.40 & -2.9 & 3.70 & 1.8 & -0.02 & 2.1 \\
\hline pH 5.0 & 4.20 & 25.0 & 2.26 & 8.9 & 0.43 & 4.1 \\
\hline $\mathrm{pH} 6.0$ & 4.50 & 38.4 & 5.46 & 6.1 & 0.29 & 5.7 \\
\hline $\mathrm{pH} 7.0$ & 4.80 & 34.0 & 8.84 & 16.2 & 0.16 & 2.5 \\
\hline $\mathrm{pH} 8.0$ & 4.30 & 25.9 & 2.36 & 6.7 & 0.19 & 3.8 \\
\hline pH 9.0 & 4.60 & 39.6 & 5.30 & 13.4 & 0.19 & 4.4 \\
\hline
\end{tabular}

chamber Tewameter ${ }^{\circledR}$ TM 300 (Courage \& Khazaka Electronic $\mathrm{GmbH}$, Cologne, Germany), and a metal stand was used to hold the probe horizontally to maintain a constant applied pressure on the skin to reduce movement artifacts [52]. It is accepted that there is no optimum TEWL value for healthy skin and that there is considerable heterogeneity among studies. However, in one study using the open-chamber method, for individuals under 65 years of age, low values of TEWL $\left(\leq 10 \mathrm{~g} / \mathrm{h} / \mathrm{m}^{2}\right)$ were reported for the volar forearm [15]. By contrast, $\mathrm{SCH}$ values as determined using capacitance principles are generally characterized into three skin types depending on whether they are very dry i.e., $<30$ arbitrary units (AUs), dry 30-40 AUs, or normal moist well-hydrated skin i.e., $>40$ AUs [53]. Typical skin surface $\mathrm{pH}$ has been reported to be within 4.5-5.0 in the forearm region, although variation is evident even across the same anatomical region [54]. All measurement probes were a part of the Multiprobe Adapter MPA9 system (Courage \& Khazaka Electronic GmbH, Cologne, Germany).

\section{Study Procedures}

Participants attended the laboratory on two separate study visits, 2 weeks apart. All tests were performed on the volar aspect of both forearms as it represents an easily accessible site commonly used in dermatological research, thus facilitating comparison with other studies. At the main study visit, baseline (BL) measurements of TEWL and skin surface $\mathrm{pH}$ were taken on six areas $(20 \mathrm{~mm} \times$ $20 \mathrm{~mm}$, three in each forearm) at contralateral locations. Each test area was separated by a distance of $40 \mathrm{~mm}$, determined using a ruler (Fig. 1a). Then, the different s-urine solutions were applied on five sites using HillTop chambers $(25 \mathrm{~mm}$, HillTop Research Inc., Saint Petersburg, FL, USA), saturated with $500 \mu \mathrm{L}$ s-urine, and secured in place with transpore adhesive tape (3M, Minneapolis, MN, USA). The remaining site served as the untreated control, as illustrated in Figure 1b. The order of s-urine solutions was randomized among participants using a Latin square. After a 2-h exposure period, the treatments were removed, and any excess moisture was removed by pat drying the skin with filter papers to ensure that what is measured is TEWL and not wet skin [55]. Then, biophysical measurements were repeated at all six sites (Fig. 1c). In the subsequent visit, $\mathrm{BL}$ skin $\mathrm{pH}$ measurements were obtained on four areas in both forearms, and two acidic (pH 5.0 and pH 6.0) and one alkaline ( $\mathrm{pH}$ 8.0) s-urine solutions were applied for $2 \mathrm{~h}$ on the skin, with the remaining site serving as the untreated control. 


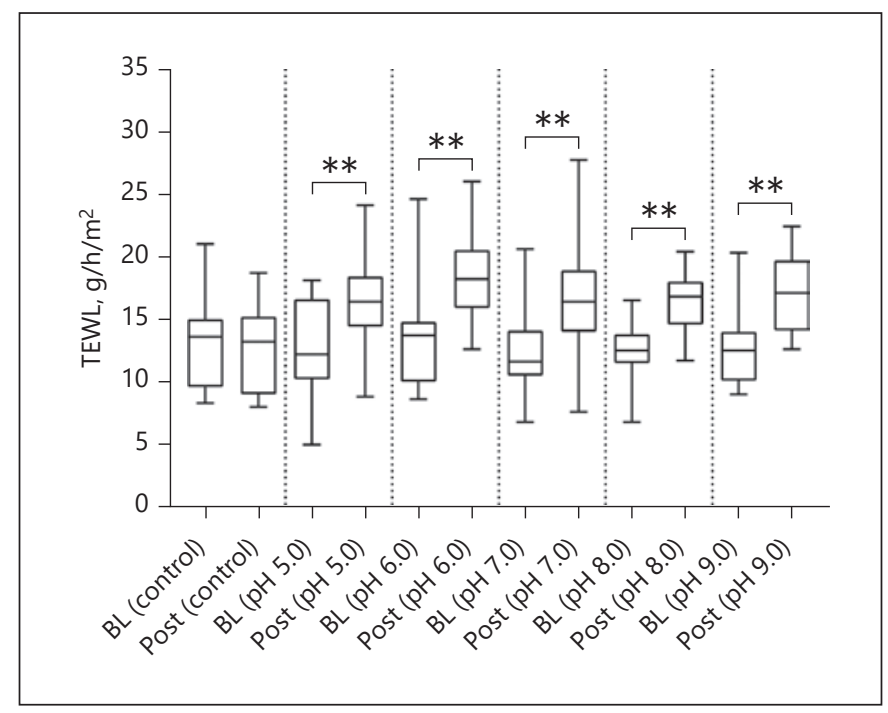

Fig. 2. Box and whisker plots for TEWL measurement at BL and following exposure to s-urine solutions. All s-urine solutions caused a significant increase in TEWL compared to BL values $(p<$ 0.001 in all cases). There were no significant differences between solutions $(p=0.066)$.

Following that, treatments were removed, and the skin was pat dried, as previously. Skin surface $\mathrm{pH}$ was recorded immediately and then every 5 mins for a total period of 40 mins.

\section{Data Analysis}

Each site served as its own control. For skin integrity parameters, data are expressed at $\mathrm{BL}$ and after each challenge as median and interquartile ranges (25th to 75th percentiles) and presented in box plots, created with GraphPad Prism 8 (GraphPad Software, San Diego, CA, USA). Table 1 also summarizes median differences and the corresponding \% change from BL values. A line graph, showing medians with interquartile range, was also plotted to show changes in skin $\mathrm{pH}$ over time after the different challenges. All statistics were performed in SPSS version 25 (IBM Corporation, Armonk, NY, USA). Considering the small sample size ( $n=$ 15), non-normal distribution of the results was assumed, and changes in biophysical measures from BL were determined by Wilcoxon signed-rank tests. Differences between s-urine solutions were assessed using the Friedman test followed by Wilcoxon signed-rank tests, respectively. A significance level of 5\% i.e., $p<$ 0.05 was considered statistically significant.

\section{Results}

\section{Participants}

The study was completed by 15 healthy participants ( 7 males, 8 females; mean age \pm SD: $34.2 \pm 12$ ), who were recruited from the staff and student population of the

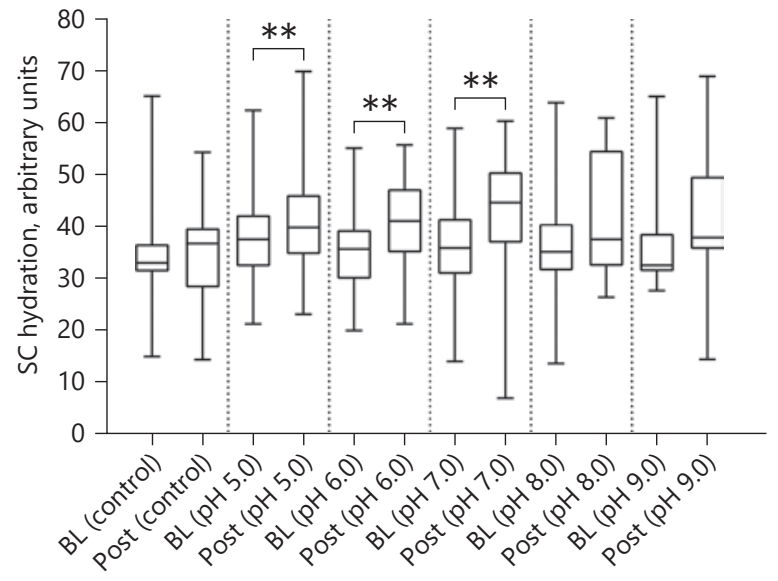

Fig. 3. Box and whisker plots for $\mathrm{SCH}$ at $\mathrm{BL}$ and following exposure to s-urine solutions. Most s-urine solutions caused a significant increase in TEWL compared to BL values $(p=0.004$ for $\mathrm{pH} 5.0, p$ $=0.012$ for $\mathrm{pH} 6.0, p=0.004$ for $\mathrm{pH} 7.0$ ). There were no significant differences for solutions with a $\mathrm{pH}$ of 8.0 and $9.0(p=0.069$ and $p$ $=0.078$, respectively).

University of Southampton. All volunteers participated in the main study, which explored the effects of s-urine of varying $\mathrm{pH}$ ( $\mathrm{pH}$ 5.0-9.0) on the functional characteristics of skin integrity. Of those, five (mean age \pm SD: $44 \pm$ 12.30, 2 males, 3 females) participated in the subsequent study to investigate the temporary changes in skin $\mathrm{pH}$ when exposed to urine solutions of $\mathrm{pH} 5.0,6.0$, and 8.0.

\section{Skin Integrity}

After exposure to s-urine solutions at different $\mathrm{pH}$ values, an increase in TEWL, SCH, and skin surface $\mathrm{pH}$ compared to BL values was revealed, as indicated in Table 1 . For TEWL, these differences were statistically significant $(p<0.001$, in all cases, Fig. 2$)$, with a median increase ranging from $25 \%$ to $40 \%$. However, there was no significant difference in the degree of TEWL increase between the s-urine solutions at different $\mathrm{pH}$ values $(p=0.066)$. In addition, there was a minimal change in TEWL at the control site, which was not statistically significant from $\mathrm{BL}(p=0.320)$. For $\mathrm{SCH}$ (Fig. 3), the corresponding percentage increases from BL were 8.9\%, 6.1\%, 16.2\%, 6.7\%, and $13.4 \%$ for $\mathrm{pH}$ values of 5.0, 6.0,7.0,8.0, and 9.0, respectively. These differences were statistically significant for three of the $\mathrm{pH}$ solutions $(p=0.004$ for $\mathrm{pH}$ 5.0, $p=$ 0.012 for $\mathrm{pH} 6.0, p=0.004$ for $\mathrm{pH} 7.0$ ), but not for the so- 


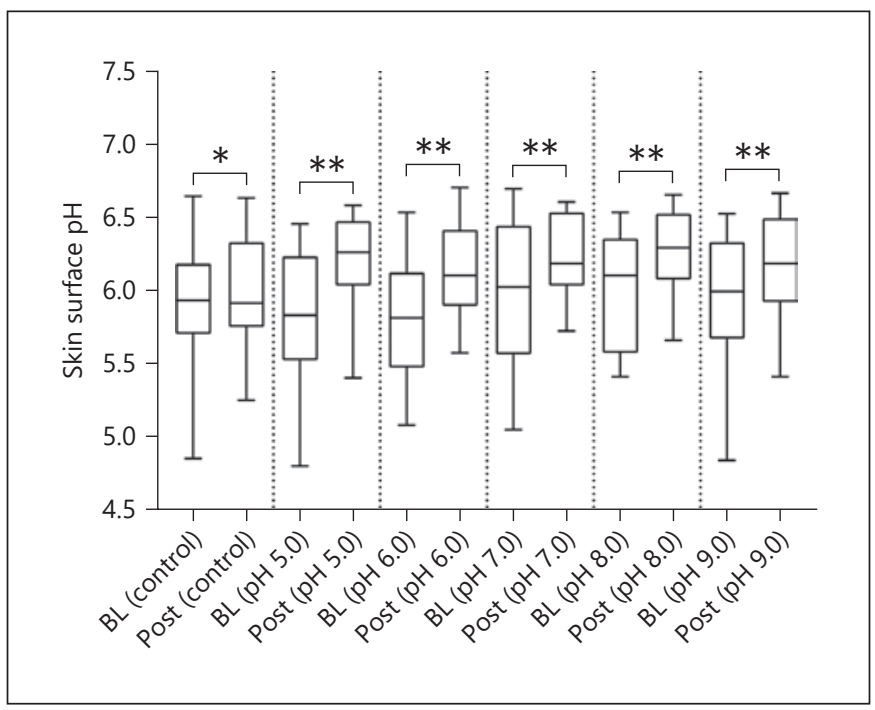

Fig. 4. Box and whisker plots for skin surface $\mathrm{pH}$ at $\mathrm{BL}$ and following exposure to s-urine solutions. Significant increases in $\mathrm{pH}$ were observed at all skin sites, including the control $(p=0.038$ for control, $p=0.001$ for $\mathrm{pH} 5.0, p=0.002$ for $\mathrm{pH} 6.0, p=0.008$ for $\mathrm{pH}$ $7.0, p=0.002$ for $\mathrm{pH} 8.0, p=0.004$ for $\mathrm{pH} 9.0)$. No significant differences were found between the s-urine solutions $(p=0.302)$.

lutions of $\mathrm{pH} 8.0$ and 9.0 ( $p>0.05$ in both cases). However, the differences between the effects of s-urine solutions were not statistically significant $(p=0.339)$. In addition, there was a minimal change in skin hydration at the control site, which was not statistically significant from BL $(p=0.865)$. Skin surface $\mathrm{pH}$ (Fig. 4) was also shown to increase after exposure, with a median increase ranging from $2.5 \%$ to $5.7 \%$, representing a statistically significant difference in all $\mathrm{pH}$ s-urine solutions $(p=$ 0.001 for $\mathrm{pH} 5.0, p=0.002$ for $\mathrm{pH} 6.0, p=0.008$ for $\mathrm{pH}$ $7.0, p=0.002$ for $\mathrm{pH} 8.0, p=0.004$ for $\mathrm{pH} 9.0$ ). However, there was no significant difference in the degree of skin $\mathrm{pH}$ increase between the s-urine solutions at different $\mathrm{pH}$ values $(p=0.302)$. It was interesting to note that the difference in skin $\mathrm{pH}$ at the control site was also found to be statistically significant $(p=0.038)$.

\section{Skin's Buffering Capacity}

A transient rise in median skin $\mathrm{pH}$ from $\mathrm{BL}$ was observed after exposure to s-urine solutions ranging from 0.55 to 0.61 . However, $\mathrm{pH}$ value was restored back to $\mathrm{BL}$ levels within $5 \mathrm{~min}$ and remained relatively constant by the end of measurements, as shown in Figure 5.

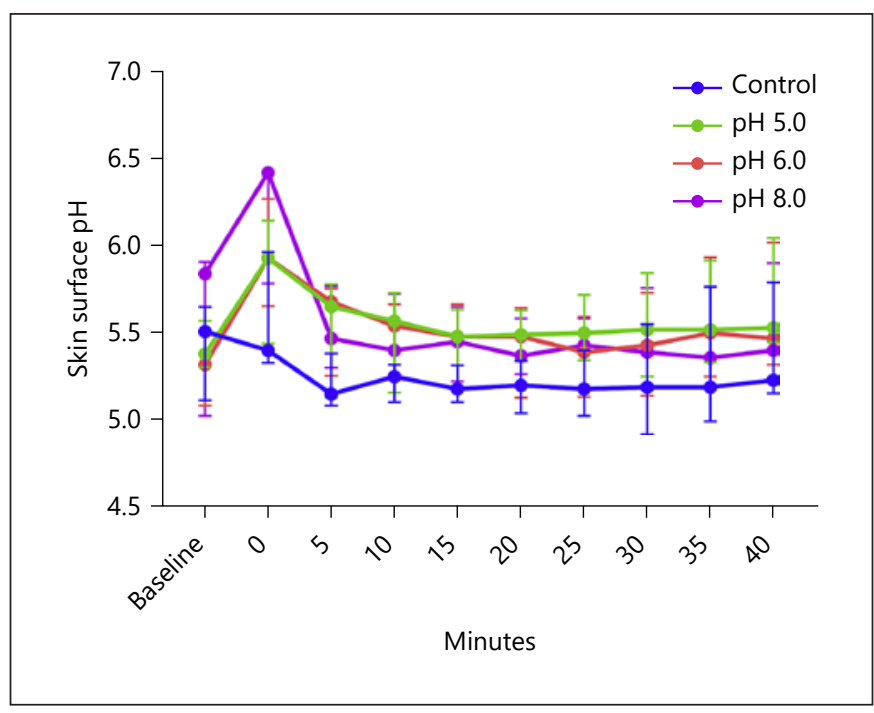

Fig. 5. The buffering capacity of the skin following exposure to surine. The skin's buffering capacity was investigated after exposure to different s-urine solutions ( $\mathrm{pH} 5.0,6.0$ and $8.0 \pm 0.7$ ). Note that after an initial increase in $\mathrm{pH}$ in all skin sites, skin $\mathrm{pH}$ returns to BL values within 5 min post-application.

\section{Discussion}

This study examined the effects of s-urine solutions of different physiologically relevant $\mathrm{pH}$ ( $\mathrm{pH}$ 5.0-9.0) on important biophysical characteristics of healthy skin integrity, namely TEWL, $\mathrm{SCH}$, and skin $\mathrm{pH}$. Although it has been reported that prolonged exposure of the skin to urine disrupts skin barrier function, maceration, and elevates skin $\mathrm{pH}$ [37], the exact mechanism by which urine and its inherent $\mathrm{pH}$ contribute to IAD has not been reported so far.

Exposure to s-urine solutions for $2 \mathrm{~h}$ caused an increase in TEWL and SCH, indicating skin barrier disruption and overhydration of the epidermis, although the effects were not $\mathrm{pH}$ dependent. An increase in cutaneous $\mathrm{pH}$ was also evident, although these changes were found to be transient, as $\mathrm{pH}$ values were rapidly restored to $\mathrm{BL}$ within 5 min, due to the inherent buffering capacity of healthy skin. This is of clinical relevance as we previously demonstrated that damaged skin characterized by a compromised buffering capacity and disturbance of the acid mantle, as demonstrated with elderly adults [56], presents an increased permeability to irritants [35]. Taken together, these findings suggest that the use of $\mathrm{pH}$-balanced cleansers should be used in skin care regimens to maintain the skin acid mantle or products to keep the amino acid pool 
of the epidermis constant, primarily responsible for the buffering capacity of the skin [57], may provide an effective prevention strategy for IAD. In particular, buffered skin care products and cleansers containing amino acid surfactants, such as glycinates, sarcosinates, and glutamates, are superior and milder to the skin than the commonly used anionic sulphate surfactants and can therefore be used as cleansing agents to maintain an optimal $\mathrm{pH}$ value [58-60]. Our findings are in contrast with a previous study which reported that an increase in urinary $\mathrm{pH}$ is associated with more severe disruption of barrier integrity [39]. This could be attributed to discrepancies in study designs with respect to exposure time and the degree of alkalinity of solutions. In particular, Larner et al. [39] employed alkaline urinary values $(\mathrm{pH} 7.9-10.7)$, while this study investigated a range of urinary values from $\mathrm{pH} 5.0$ to 9.0 closely resembling the $\mathrm{pH}$ of biological urine.

It is currently widely accepted among clinicians that patients with urinary incontinence alone are less likely to develop IAD $[4,6]$. However, when combined with other factors skin damage, inflammation and IAD can occur. In particular, the presence of bacteria in urine is commonly found in patients with urinary incontinence [61], and indeed, bacteria contaminated urine has been recognized as a risk factor for IAD [62]. Therefore, future studies need to examine the mechanisms of IAD following combined exposure of skin to urine and common uropathogens associated with IAD, including Pseudomonas aeruginosa and Proteus mirabilis, which can also contribute to $\mathrm{pH}$ elevation due to its high urease activity [63].

\section{Limitations}

We acknowledge that this study was conducted on a relatively young cohort of healthy volunteers, and although age is not considered a risk factor of IAD, it is associated with a high prevalence of incontinence [64], and older adults are characterized by a diminished skin buffering capacity due to decreased barrier function $[30,56]$. Additionally, the prescribed 2-h exposure period was practical for experimental testing on volunteers; however, with the increasing use of absorbent pads to contain incontinence, changing intervals can vary and urine may remain in contact with the skin for longer periods.

\section{Conclusions}

This study demonstrated that urine disrupts barrier function and overhydrates the epidermis, which is characteristics of macerated skin, but alone appears not to damage the protective acid mantle, which is critical in maintaining the integrity of the skin. Future work needs to examine the effects of urine combined with bacteria responsible for $\mathrm{pH}$ elevation in patients with urinary incontinence. This would further enhance our understanding of IAD development in patients with urinary incontinence.

\section{Acknowledgments}

The authors would like to express their gratitude to all the volunteers who participated in this study.

\section{Statement of Ethics}

This study was approved by the Ethics Committee of the Faculty of Health Sciences, University of Southampton (approval number 9349). Volunteers were recruited from the staff and student populations of the University of Southampton via word of mouth and a study poster. All participants provided written informed consent prior to the start of the study and a copy of the consent form was given to each. No incentives for participation were offered. The study complied fully with the principles outlined in the Declaration of Helsinki.

\section{Conflict of Interest Statement}

The authors have no conflicts of interest to declare.

\section{Funding Sources}

This work was supported by a PhD studentship offered by the University of Southampton.

\section{Author Contributions}

All authors made substantial contributions to the conception and design of the study; S.K. performed acquisition of data or analysis and interpretation of data; S.K. and D.V. involved in drafting the manuscript or revising it critically for important intellectual content; all authors gave final approval of the version to be published. S.K. agreed to be accountable for all aspects of the work in ensuring that questions related to the accuracy or integrity of any part of the work are appropriately investigated and resolved.

\section{Data Availability Statement}

All data generated or analysed during this study are included in this article. Further enquiries can be directed to the corresponding author. 


\section{References}

1 World Health Organization. International classification of diseases for mortality and morbidity statistics (11th Revision). [Internet]; World Health Organization: 2018. Available from: https://icd.who.int/en.

2 Beeckman D, Gray M, Campbell J, Campbell $\mathrm{K}$, Chimentão D, Coyer F, et al. Incontinenceassociated dermatitis: moving prevention forward. Proceedings of the Global IAD Expert Panel. Wounds Int; 2015. p. 1-21.

3 Hahnel E, Lichterfeld A, Blume-Peytavi U, Kottner J. The epidemiology of skin conditions in the aged: a systematic review. J Tissue Viability. 2017;26(1):20-8.

4 Gray M, Giuliano KK. Incontinence-associated dermatitis, characteristics and relationship to pressure injury: a multisite epidemiologic analysis. J Wound Ostomy Continence Nurs. 2018;45(1):63-7.

5 Lachenbruch C, Ribble D, Emmons K, VanGilder C. Pressure ulcer risk in the incontinent patient: analysis of incontinence and hospital-acquired pressure ulcers from the International Pressure Ulcer PrevalenceTM Survey. J Wound Ostomy Continence Nurs. 2016; 43(3):235-41.

6 Kayser SA, Phipps LA, Vangilder CA, Lachenbruch $\mathrm{C}$. Examining prevalence and risk factors of incontinence-associated dermatitis using the international pressure ulcer prevalence survey. J Wound Ostomy Continence Nurs. 2019;46:285-90.

7 Campbell JL, Coyer FM, Osborne SR. Incontinence-associated dermatitis: a cross-sectional prevalence study in the Australian acute care hospital setting. Int Wound J. 2016; 13(3):403-11.

8 Johansen E, Bakken LN, Duvaland E, Faulstich J, Hoelstad HL, Moore Z, et al. Incontinence-associated dermatitis (IAD): prevalence and associated factors in 4 hospitals in Southeast Norway. J Wound Ostomy Continence Nurs. 2018;45(6):527-31.

9 Boronat-Garrido X, Kottner J, Schmitz G, Lahmann N. Incontinence-associated dermatitis in nursing homes: prevalence, severity, and risk factors in residents with urinary and/or fecal incontinence. J Wound Ostomy Continence Nurs. 2016;43(6):630-5.

10 Clark M, Semple MJ, Ivins N, Mahoney K, Harding K. National audit of pressure ulcers and incontinence-associated dermatitis in hospitals across Wales: a cross-sectional study. BMJ Open. 2017;7(8):e015616.

11 Van Damme N, Clays E, Verhaeghe S, Van Hecke A, Beeckman D. Independent risk factors for the development of incontinence-associated dermatitis (category 2) in critically ill patients with fecal incontinence: a cross-sectional observational study in 48 ICU units. Int J Nurs Stud. 2018;81:30-9.

12 Long MA, Reed LA, Dunning K, Ying J. Incontinence-associated dermatitis in a longterm acute care facility. J Wound Ostomy Continence Nurs. 2012;39(3):318-27.
13 Bliss DZ, Mathiason MA, Gurvich O, Savik K, Eberly LE, Fisher J, et al. Incidence and predictors of incontinence-associated skin damage in nursing home residents with new-onset incontinence. J Wound Ostomy Continence Nurs. 2017;44(2):165-71.

14 Campbell J, Cook JL, Doubrovsky A, Vann A, McNamara G, Coyer F. Exploring incontinence-associated dermavvtitis in a single center intensive care unit: a longitudinal point prevalence survey. J Wound Ostomy Continence Nurs. 2019;46(5):401-7.

15 Akdeniz M, Gabriel S, Lichterfeld-Kottner A, Blume-Peytavi U, Kottner J. Transepidermal water loss in healthy adults: a systematic review and meta-analysis update. Br J Dermatol. 2018;179(5):1049-55.

16 Eyerich S, Eyerich K, Traidl-Hoffmann C, Biedermann T. Cutaneous barriers and skin immunity: differentiating a connected network. Trends Immunol. 2018;39(4):315-27.

17 Schade H, Marchionini A. Der säuremantel der haut (nach gaskettenmessungen). Klin Wochenschr. 1928;7(1):12-4.

18 Ali SM, Yosipovitch G. Skin pH: from basic science to basic skin care. Acta Derm Venereol. 2013;93(3):261-7.

19 Aly R, Shirley C, Cunico B, Maibach HI. Effect of prolonged occlusion on the microbial flora, $\mathrm{pH}$, carbon dioxide and transepidermal water loss on human skin. J Invest Dermatol. 1978 Dec;71(6):378-81.

20 Korting HC, Hübner K, Greiner K, Hamm G, Braun-Falco O. Differences in the skin surface $\mathrm{pH}$ and bacterial microflora due to the longterm application of synthetic detergent preparations of $\mathrm{pH} 5.5$ and $\mathrm{pH}$ 7.0. Results of a crossover trial in healthy volunteers. Acta Derm Venereol. 1990;70(5):429-31.

21 Elias PM. Structure and function of the stratum corneum extracellular matrix. J Invest Dermatol. 2012;132(9):2131-3.

22 Mauro T, Grayson S, Gao WN, Man MQ, Kriehuber E, Behne M, et al. Barrier recovery is impeded at neutral $\mathrm{pH}$, independent of ionic effects: implications for extracellular lipid processing. Arch Dermatol Res. 1998;290(4): 215-22.

23 Hachem JP, Crumrine D, Fluhr J, Brown BE, Feingold KR, Elias PM. pH directly regulates epidermal permeability barrier homeostasis, and stratum corneum integrity/cohesion. J Invest Dermatol. 2003;121(2):345-53.

24 Rippke F, Schreiner V, Schwanitz HJ. The acidic milieu of the horny layer: new findings on the physiology and pathophysiology of skin pH. Am J Clin Dermatol. 2002;3(4):26172.

25 Hachem JP, Man MQ, Crumrine D, Uchida $\mathrm{Y}$, Brown BE, Regiers V, et al. Sustained serine proteases activity by prolonged increase in $\mathrm{pH}$ leads to degradation of lipid processing enzymes and profound alterations of barrier function and stratum corneum integrity. J Invest Dermatol. 2005;125(3):510-20.
26 Bouwstra JA, Gooris GS, Dubbelaar FE, Weerheim AM, Ponec M. pH, cholesterol sulfate, and fatty acids affect the stratum corneum lipid organization. J Investig Dermatol Symp Proc. 1998;3:69-74.

27 Hachem J-P, Houben E, Crumrine D, Man $\mathrm{MQ}$, Schurer N, Roelandt T, et al. Serine protease signaling of epidermal permeability barrier homeostasis. J Invest Dermatol. 2006; 126(9):2074-86.

28 Fluhr JW, Feingold KR, Elias PM. Transepidermal water loss reflects permeability barrier status: validation in human and rodent in vivo and ex vivo models. Exp Dermatol. 2006; 15(7):483-92.

29 Ichikawa-Shigeta Y, Sugama J, Sanada H, Nakatani T, Konya C, Nakagami G, et al. Physiological and appearance characteristics of skin maceration in elderly women with incontinence. J Wound Care. 2014;23(1):18-30.

30 Fujimura T, Makino M, Takagi M, Maki K, Murakami E, Tasaka Y, et al. The influence of incontinence on the characteristic properties of the skin in bedridden elderly subjects. Int J Dermatol. 2016;55(5):e234-40.

31 Koudounas S, Bader DL, Voegeli D. Investigating the release of inflammatory cytokines in a human model of incontinence-associated dermatitis. J Tissue Viability. 2021;30(3):42733.

32 Armbruster CE, Mobley HLT, Pearson MM. Pathogenesis of Proteus mirabilis infection. EcoSal Plus. 2018;8(1):10.

33 Beele H, Smet S, Van Damme N, Beeckman $\mathrm{D}$, Beele $\mathrm{H}$, Smet $\mathrm{S}$, et al. Incontinence-associated dermatitis: pathogenesis, contributing factors, prevention and management options. Drugs Aging. 2018;35(1):1-10.

34 Andersen PH, Bucher AP, Saeed I, Lee PC, Davis JA, Maibach HI. Faecal enzymes: in vivo human skin irritation. Contact Dermatitis. 1994;30(3): 152-8.

35 Koudounas S, Bader DL, Voegeli D. Elevated skin $\mathrm{pH}$ is associated with an increased permeability to synthetic urine. J Wound Ostomy Continence Nurs. 2021;48(1):61-7.

36 Koudounas S, Minematsu T, Mugita Y, Tomida S, Nakai A, Nakagami G, et al. Inhibiting effect of synthetic urine on the growth and mobility of Pseudomonas aeruginosa, Escherichia coli, Proteus mirabilis and Klebsiella pneumoniae shifts to a promoting effect during culture. J Nurs Sci Eng. 2021;8:220-9.

37 Beeckman D, Schoonhoven L, Verhaeghe S, Heyneman A, Defloor T. Prevention and treatment of incontinence-associated dermatitis: literature review. J Adv Nurs. 2009;65(6): 1141-54.

38 Phipps L, Gray M, Call E. Time of onset to changes in skin condition during exposure to synthetic urine: a Prospective Study. J Wound Ostomy Continence Nurs. 2019;46(4):31520. 
39 Larner J, Matar H, Goldman VS, Chilcott RP. Development of a cumulative irritation model for incontinence-associated dermatitis. Arch Dermatol Res. 2015;307(1):39-48.

40 Bono MJ, Reygaert WC. Urinary tract infection. StatPearls. StatPearls Publishing; 2019.

41 Rose C, Parker A, Jefferson B, Cartmell E. The characterization of feces and urine: a review of the literature to inform advanced treatment technology. Crit Rev Environ Sci Technol. 2015;45(17):1827-79.

42 Brunzel NA. Fundamentals of urine \& body fluid analysis. 4th ed. Elsevier Saunders.; 2016. p. 85-90.

43 Rogiers V. EEMCO guidance for the assessment of transepidermal water loss in cosmetic sciences. Skin Pharmacol Appl Skin Physiol. 2001;14(2):117-28.

44 Berardesca E. European Group for efficacy measurements on cosmetics and other topical products (EEMCO). EEMCO guidance for the assessment of stratum corneum hydration: electrical methods. Ski Res Technol. 1997;3(2):126-32.

45 Parra JL, Paye M; EEMCO Group. EEMCO guidance for the in vivo assessment of skin surface $\mathrm{pH}$. Skin Pharmacol Appl Skin Physiol. 2003;16(3):188-202.

46 Du Plessis J, Stefaniak A, Eloff F, John S, Agner T, Chou TC, et al. International guidelines for the in vivo assessment of skin properties in non-clinical settings: part 2. Transepidermal water loss and skin hydration. Ski Res Technol. 2013;19(3):265-78.

47 Stefaniak AB, Du Plessis J, John SM, Eloff F, Agner T, Chou TC, et al. International guidelines for the in vivo assessment of skin properties in non-clinical settings: part 1.pH. Ski Res Technol. 2013;19(2):59-68.
48 Schulz KF, Altman DG, Moher D. CONSORT 2010 statement: updated guidelines for reporting parallel group randomised trials. BMJ. 2010;340:c332.

49 Voegeli D. The effect of washing and drying practices on skin barrier function. J Wound Ostomy Continence Nurs. 2008;35(1):84-90.

50 Lodén M. Effect of moisturizers on epidermal barrier function. Clin Dermatol. 2012;30(3): 286-96.

51 Mayrovitz HN, Sims N. Biophysical effects of water and synthetic urine on skin. Adv Skin Wound Care. 2001;14(6):302-8.

52 Fader M, Clark-O'Neill SR, Wong WK, Runeman B, Farbrot A, Cottenden AM. Development and preliminary testing of a standardized method for quantifying excess water in over-hydrated skin using evaporimetry. Physiol Meas. 2011;32(3):305-17.

53 Heinrich U, Koop U, Leneveu-Duchemin MC, Osterrieder K, Bielfeldt S, Chkarnat C, et al. Multicentre comparison of skin hydration in terms of physical-, physiological- and product-dependent parameters by the capacitive method (Corneometer CM 825). Int J Cosmet Sci. 2003;25(1-2):45-53.

54 Kleesz P, Darlenski R, Fluhr JW. Full-body skin mapping for six biophysical parameters: baseline values at 16 anatomical sites in 125 human subjects. Skin Pharmacol Physiol. 2012;25(1):25-33.

55 Imhof RE, De Jesus ME, Xiao P, Ciortea LI, Berg EP. Closed-chamber transepidermal water loss measurement: microclimate, calibration and performance. Int J Cosmet Sci. 2009; 31(2):97-118.

56 Levin J, Maibach HI. Buffering capacity considerations in the elderly. Textbook Aging Skin Springer: 2015. p. 1-13.
57 Vermeer DJ, de Jong JC, Lenstra JB. The significance of amino-acids for the neutralization by the skin. Dermatologica. 1951;103(1): $1-18$.

58 Ananthapadmanabhan KP. Amino-acid surfactants in personal cleansing (review). Tenside Surfactants Deterg. 2019;56(5):378-86.

59 Mehlich A, Doberenz C, Janssens-Böcker C. Acidification of the skin and maintenance of the physiological skin $\mathrm{pH}$ value by buffered skin care products formulated around $\mathrm{pH} 4$. J Cosmet Dermatol Sci Appl. 2021;11(01):44.

60 Okasaka M, Kubota K, Yamasaki E, Yang J, Takata S. Evaluation of anionic surfactants effects on the skin barrier function based on skin permeability. Pharm Dev Technol. 2019; 24(1):99-104.

61 Brubaker L, Nager CW, Richter HE, Visco A, Nygaard I, Barber MD, et al. Urinary bacteria in adult women with urgency urinary incontinence. Int Urogynecol J. 2014;25(9):117984.

62 Ichikawa-Shigeta Y, Yusuf S, Sugama J, Supriadi S, Sanada H, Konya C. Risk assessment tool for incontinence-associated dermatitis in elderly patients combining tissue tolerance and perineal environment predictors: a prospective clinical study. Chronic Wound Care Manag Res. 2014;1:41-7.

63 Mugita Y, Nakagami G, Minematsu T, Kitamura A, Sanada H. Combination of urease inhibitor and antiseptic inhibits urea decomposition-induced ammonia production by Proteus mirabilis. Int Wound J. 2020;17:1558-65.

64 Kottner J, Blume-Peytavi U, Lohrmann C, Halfens R. Associations between individual characteristics and incontinence-associated dermatitis: a secondary data analysis of a multi-centre prevalence study. Int J Nurs Stud. 2014;51:1373-80. 